\title{
La guía paterna en el consumo televisivo: un modelo cuantitativo y cualitativo en el aprendizaje de contenidos
}

\author{
Carmen Marta Lazo \\ Directora Académica de la Facultad de Comunicación \\ de la Universidad San Jorge (Zaragoza). \\ cmarta@usj.es
}

\begin{abstract}
Resumen
Las pautas que los padres ofrecen a sus hijos en cuanto a consumo televisivo son fundamentales en la forma de interacción que el niño tenga con el medio. El control paterno ayuda al niño a aprender a establecer criterios relativos no sólo a la cantidad de exposición diaria, sino también en lo concerniente a los programas que resultan más o menos acordes para su edad. El estudio pone de manifiesto que los niños que acostumbran a dialogar con sus padres respecto a lo visto en televisión presentan mayores niveles de actividad en el proceso de visionado y saben interpretar con mayor claridad el contenido de los mensajes televisivos.
\end{abstract}

\begin{abstract}
Parents' behavioural patterns as regards TV use are defining of the child's interaction with the medium. To all appearances, parents' supervision helps the child establish a set of personal criteria concerning both duration and frequency of exposure, as well as age appropriateness. Furthermore, as our research evinces, children in the habit of discussing TV shows with their parents reveal a higher degree of activeness in their visualisation process together with a notably finer ability of disclosing and decoding content in TV messages.
\end{abstract}

Palabras clave: Televisión, niños, consumo, diálogo, padres, educación.

Key words: Television, children, consumption, dialogue, parents, education.

\section{LAS PAUTAS DE LOS PADRES, FUNDAMENTALES EN LA RELACIÓN ENTRE NIÑO Y MEDIO TELEVISIVO}

os padres, por encontrarse en el contexto inmediato en el que se desarrolla la interacción con el medio televisivo, son una de las principales fuentes de información en la "lectura de imágenes". El niño une las adquisiciones que recibe de los padres al caudal de conocimientos que posee respecto a la televisión, relacionados con la manera de entender el significado de los mensajes y con las formas de presentar los contenidos, y ello va nutriendo sus referentes en la reinterpretación de los contenidos. Independientemente de las nociones paternas 
La guía en el consumo televisivo...

respecto a las técnicas televisivas en el plano de la realización, el diálogo con los adultos supone un óptimo punto de partida para que el niño enriquezca la primera significación que otorga a los mensajes y se replantee de qué otras maneras o con qué otras lecturas los interpretan otras personas. En definitiva, es importante que aprecie que su forma de entenderlos no es la única ni es definitiva.

La compañía de los padres durante el proceso de visionado es de gran ayuda para ofrecer orientaciones relacionadas con los posibles valores negativos o "contravalores" que se desprenden de determinados mensajes y que los niños no siempre alcanzan a ver. A raíz de los filtros que los adultos les proporcionen y de la contextualización de aquello que no lleguen a entender, los pequeños activarán mecanismos de defensa para encender una "luz" en futuras aproximaciones al medio en las que puedan realizar un consumo en solitario e irán adquiriendo experiencia para realizar una "lectura crítica" de los mensajes.

Otros de los parámetros que los progenitores o tutores pueden enseñarles son la diferenciación entre realidad y ficción, los géneros que representan la realidad y los que se fundamentan en lo imaginario; los aspectos críticos que se esconden detrás de algunos mensajes y la finalidad de los mismos; $y$, por supuesto, el modo de discernir entre contenidos destinados a ellos como público objetivo y aquellos que son para adultos y que no deberían ver por su corta edad, en pro de su correcto desarrollo evolutivo. Por ello, que el niño realice un consumo más o menos responsable cuando se encuentre solo delante de la pantalla dependerá de la guía previa que sus padres le hayan ofrecido y de cómo estos hayan intervenido en el modelo perceptivo de sus hijos, modelo que en las etapas de la temprana infancia es imprescindible tutelar.

Asimismo, compartir junto con los hijos el tiempo dedicado al medio supone una forma de saber cuáles son sus gustos, preferencias y actitudes, lo que ayuda a los padres a conocer los usos que los más pequeños harán del medio cuando no se encuentren junto a ellos viendo la televisión. También es una "carta de confianza" para que el niño les comente lo que ha visto en solitario y les pregunte, para resolver sus dudas, todo aquello que no haya logrado entender o le haya llamado la atención.

En contraposición, el consumo habitual sin compañía alguna y la falta de diálogo respecto a lo visto en televisión pueden afectar, si el sujeto infantil no está preparado por otros cauces, como pueda ser el contexto escolar, a una falta de cuestionamiento de lo emitido y a una ausencia de criterio respecto a todo aquello que pueda perjudicar su aprendizaje y desarrollo desde edades tempranas y a lo largo de todo su proceso evolutivo. En este sentido, Aguaded (1999) apunta que "la actitud familiar ante la televisión tiene mayor trascendencia si consideramos que ésta comienza a influir de forma sistemática desde la primera infancia, ya que los modelos paternos de esta época se mantienen en los períodos de mayor plasticidad en la evolución de los niños"

${ }^{1}$ AGUADED, J. I. (1999): Convivir con la televisión. Familia, educación y recepción televisiva. Barcelona, Paidós, pág. 31. 


\section{DISTINTAS MODALIDADES DE VER TELEVISIÓN: CONSUMO DE- MOCRÁTICO, CONSUMO AUTORITARIO Y CONSUMO EN SOLITARIO.}

Además del diálogo habitual con los padres en referencia a los contenidos emitidos en televisión, el modo de consumo también afecta a los usos y actitudes que el niño tenga ante el medio.

Podemos diferenciar entre diversas maneras de ver la televisión en el contexto perceptivo del hogar:

- consumo democrático: forma de compartir el medio asentada en las bases de que cada vez elige un miembro de la familia lo que desea ver o se ve lo que decide, en cada caso, la mayoría;

- consumo autoritario: modalidad en la que, en la mayoría de las ocasiones, es el adulto quien se hace con "el mando" e impone al resto lo que hay que ver;

- consumo en solitario: modo unilateral de acercarse a la pantalla, de manera aislada, sin compartir con nadie el tiempo de visionado. Si bien tradicionalmente en la mayoría de los hogares sólo se contaba con un receptor de televisión emplazado en el salón, como lugar principal en el que transcendía la vida de la familia, cada vez es más habitual que se cuente con una pantalla en cada habitación, aspecto que propicia esta modalidad de ver televisión;

Este tipo de circunstancias estructurales en los modos de consumir televisión repercuten en los comportamientos que el niño tenga cuando no esté junto al resto de su familia, siendo más probable que elija "lo prohibido" en la segunda de las situaciones, con todo lo que ello puede conllevar, de consumir -incluso- contenidos no recomendados para niños; mientras que en el primer caso el niño se ajustará a sus preferencias, conocidas de antemano por los adultos con los que comparte, en el más amplio sentido de la palabra, de manera habitual su tiempo de exposición al medio.

La tercera forma de consumo que planteamos es cuanto menos preocupante si tenemos en consideración que según cifras de recientes estudios un tercio de los niños españoles cuenta con equipo propio. $Y$ esto supone un mayor consumo, a veces indiscriminado, de programas sin que los padres no sólo no vigilen sino que apenas conozcan lo que sus hijos están viendo ni tampoco en qué horarios. A lo que, evidentemente, se añade una ausencia de diálogo acerca de los contenidos, una falta de contraste en la lectura de los mensajes e intercambio de opiniones y de oportunidades de preguntar a los adultos aspectos puntuales que no se entienden. 


\section{LOS PADRES NO OTORGAN LA IMPORTANCIA REQUERIDA AL CONSUMO COMPARTIDO CON SUS HIJOS NI AL DIÁLOGO ACERCA DE LOS CONTENIDOS VISTOS EN TELEVISIÓN}

Anteriormente, hemos apuntado la conveniencia de ver la televisión junto con los hijos y del diálogo respecto a los contenidos vistos, pero ¿en qué medida son frecuentes estas situaciones?, ¿de qué modo concreto afectan a las prácticas televisivas de los niños?, ¿se sienten los padres preparados para explicar a sus hijos todo aquello relacionado con las formas de construcción de los mensajes mediáticos y con las maneras de interpretar de manera crítica y razonada los significados?... Éstas son algunas de las dudas que nos surgen y a las que trataremos de dar respuesta en las siguientes líneas.

\subsection{El elevado consumo diario, un mal ejemplo}

En primer lugar, cabe advertir que el ejemplo que los adultos dan a los niños en cuanto al tiempo de visionado diario no es alentador. Las cifras de consumo muestran que los niños ven menos la televisión que sus mayores. Según datos de TN Sofres ${ }^{2}$ de la temporada 2001/2002, el promedio de lunes a domingo, en niños entre 4 y 12 años, era de 147 minutos diarios (dos horas y 27 minutos); mientras que para el total de la población alcanzaba los 219 minutos (3 horas 39 minutos), lo que significa que los niños durante el periodo citado consumieron una hora y doce minutos menos que la media de la población en general. De esta forma, los adultos mediante su propio patrón de consumo invitan a los niños a una exposición prolongada al medio.

\subsection{La televisión como principal compañera en el tiempo libre de los niños}

A ese incentivo en la elevada cantidad de consumo diario, se añade como segundo parámetro preocupante que, en muchas ocasiones, los padres no ven junto con sus hijos la televisión. Según pudimos constatar en una investigación ${ }^{3}$ realizada en el año 2002, en la que encuestamos a 440 escolares de la Comunidad de Madrid con el fin de observar tendencias en el consumo infantil, sólo un 56,1\% solía ver la televisión acompañado de sus padres. Esta circunstancia fomenta una relación unilateral de los más pequeños con la pantalla. Como consecuencia, la televisión ejerce el rol de compañera en el tiempo de ocio de los niños. Y esta función que se le otorga, como "niñera electrónica" o "institutriz", es asumida por

\footnotetext{
${ }^{2}$ Estos datos pueden consultarse y completarse en el "Estudio de la oferta y las preferencias temáticas de la audiencia televisual infantil en España" llevado a cabo por PÉREZ ORNIA, J.R. y NÚÑEZ LADEVEZE, L., publicado en TELOS, Cuadernos de Comunicación, Tecnología y Sociedad, № 54, Fundación Telefónica, págs. 103-113.

${ }^{3}$ La metodología y resultados de esta investigación están contenidos en MARTA LAZO, C. (2005): La televisión en la mirada de los niños, Madrid, Fragua.
} 
los propios padres. En este sentido, en un estudio en el que encuestamos a padres ${ }^{4}$ observamos como en los hogares que ambos miembros trabajan fuera del hogar argumentaban que "no disponen de demasiado tiempo para jugar y ver la televisión con los hijos", por lo que demandaban al medio más programas de "entretenimiento" para que los niños permanecieran ocupados. Por otro lado, a pesar que advertían que les preocupaba el tipo de contenidos negativos emitidos, así como las consecuencias que causa ver la televisión, entre las que citaban textualmente, "la falta de comunicación familiar", "la comedura de coco" o "la creación de dependencia", un $20 \%$ de los encuestados reconocía abiertamente "no comentar ni explicar a sus hijos nada de lo que ven”. Esta ausencia de diálogo se debía, entre otras razones, al desconocimiento de los formatos y contenidos, por lo que afirmaban no sentirse "capacitados para transmitir una buena información y educación televisiva a sus hijos".

Con similar proyección, en un estudio titulado "La televisión y los niños" realizado por el CIS (2000), un 25\% de los encuestados opinaba que "los padres no pueden estar en todo, y necesitan también el apoyo de los maestros y profesores para enseñar a ver la televisión a sus alumnos" y un $30 \%$ respondía que "los verdaderos responsables de lo que ven nuestros hijos en televisión son los programadores de las distintas cadenas". Únicamente, el $42 \%$ de los padres contestó que "preocuparse por los programas de televisión que ven los niños y adolescentes es una labor exclusiva de los padres".

\subsection{El diálogo con los niños respecto a lo visto en la pantalla, una práctica escasa}

Como tercer indicador, nos fijaremos precisamente en qué medida los niños dialogan con sus padres respecto a los contenidos que ven en la televisión. En la ya citada investigación realizada en el 2002, pudimos constatar que sólo un $54,3 \%$ de los encuestados acostumbraba a realizar esta práctica. Por otra parte, el grupo de amigos era con quienes más solían conversar en relación con lo visto en la pantalla (un $67,9 \%$ de la muestra) y sólo un 3,9\% lo hacía con sus profesores. A estos porcentajes, cabe añadir que un significativo 12,9\% de los escolares afirmaba que no dialogaba con nadie al respecto, situación que podemos calificar de alarmante, teniendo en consideración que estos niños tienen una relación exclusiva con el medio, sin retomar lo que ven ni intercambiar ninguna opinión, ni tan siquiera cuestionar con otras voces lo que más les preocupa o no entienden de los mensajes que se "tragan".

${ }^{4}$ MARTA LAZO, C. y DE ÁNGEL GARCíA, N. (1997): "Análisis empírico sobre la decodificación del mensaje televisivo, según el proceso evolutivo en niños de clase media de 4 a 7 años", en Actas del I Congreso Internacional de Formación y Medios (Ponencias y Comunicaciones). Segovia, Universidad de Valladolid, págs. 327-333.

${ }^{5}$ Los resultados de este estudio, que se corresponde con el no 2.391 , se encuentran publicados en el Boletín del Centro de Investigaciones Sociológicas, CIS, № 26, que puede consultarse en la web http://www.cis.es/boletin/26/tele.htm. 


\section{MODOS EN LOS QUE AFECTA EL DIÁLOGO PATERNO A LA LECTURA DE LOS MENSAJES Y A LA INTERRELACIÓN ENTRE NIÑO Y TELEVISIÓN}

Hasta aquí hemos abarcado el panorama de consumo e intercambio de lecturas que los niños realizan en el plano cuantitativo, pero de qué modo intervienen estas circunstancias en el "proceso de negociación" que los niños hacen con los mensajes. En esta parte, trataremos de explicar cómo repercuten la cantidad de visionado diario y el diálogo con los padres en la lectura de los contenidos televisivos y en el nivel de actividad que los niños mantengan en su interacción con el medio.

En la mencionada investigación, abordamos también un análisis cualitativo mediante la realización de 16 grupos de discusión en el que las variables de estudio dependientes eran el tiempo diario de exposición, repartido en dos niveles (ver la televisión más de dos horas o no llegar a este límite), y la mediación de los adultos, con otras dos categorías (la existencia habitual de diálogo con los padres respecto a los contenidos vistos en la pantalla o la ausencia de éste). Por otro lado, la variable independiente era la edad, segmentada en dos grupos: niños de 7 a 9 años y niños de 10 a 12 años.

Con el fin de determinar cómo afectaban las variables señaladas al nivel de actividad que los niños mostraran en su interrelación con el medio, confeccionamos la escala que presentamos a continuación ${ }^{6}$ :

\begin{tabular}{|c|c|c|c|c|c|c|c|}
\hline NIVEL 0 & NIVEL 1 & \multicolumn{2}{|c|}{ NIVEL 2} & \multicolumn{2}{|c|}{ NIVEL 3} & \multicolumn{2}{|c|}{ NIVEL 4} \\
\hline MUY BAJO & BAJO & \multicolumn{2}{|c|}{ MEDIO } & \multicolumn{2}{|c|}{ ALTO } & \multicolumn{2}{|c|}{ MUY ALTO } \\
\hline $\begin{array}{l}\text { - DECIDE NO } \\
\text { VER LAS IMÁ- } \\
\text { GENES }\end{array}$ & $\begin{array}{l}\text { - SE QUEDA } \\
\text { IMPASIBLE }\end{array}$ & \multicolumn{2}{|c|}{$\begin{array}{l}\text {-RESPONDE } \\
\text { CON MONO- } \\
\text { SÍLABOS }\end{array}$} & \multicolumn{2}{|c|}{$\begin{array}{l}\text {-EXPLICA EL } \\
\text { SENTIDO DEL } \\
\text { MENSAJE, EN } \\
\text { FUNCIÓN DE } \\
\text { CÓMO HA } \\
\text { COMPRENDI- } \\
\text { DO SU SIGNI- } \\
\text { FICADO }\end{array}$} & \multicolumn{2}{|c|}{$\begin{array}{l}\text {-ESTABLECE } \\
\text { RELACIONES } \\
\text { CON LO YA } \\
\text { CONOCIDO }\end{array}$} \\
\hline $\begin{array}{l}\text {-REALIZA } \\
\text { OTRAS ACTI- } \\
\text { VIDADES }\end{array}$ & $\begin{array}{l}\text {-RESPONDE } \\
\text { DE MANERA } \\
\text { GESTUAL: } \\
{ }^{*} \text { ROSTRO } \\
\text { *BRAZOS } \\
\text { * SE DESPLA- } \\
\text { ZA }\end{array}$ & \multicolumn{2}{|c|}{$\begin{array}{c}\text { - INFORMA } \\
\text { ACERCA DE } \\
\text { LO QUE MIRA }\end{array}$} & \multicolumn{2}{|c|}{$\begin{array}{c}\text {-VALORA CON } \\
\text { ARGUMEN- } \\
\text { TOS EL MEN- } \\
\text { SAJE DESDE } \\
\text { UNA VISIÓN } \\
\text { SUBJETIVA, } \\
\text { DA SU PARE- } \\
\text { CER AL RES- } \\
\text { PECTO } \\
\end{array}$} & \multicolumn{2}{|c|}{$\begin{array}{l}\text {-PARTICIPA, } \\
\text { OFRECE AL- } \\
\text { TERNATIVAS Y } \\
\text { PROPUESTAS, } \\
\text { CREA OTROS } \\
\text { ESCENA- } \\
\text { RIOS,... }\end{array}$} \\
\hline OTRA ELECCIÓN & \begin{tabular}{c|c} 
NO & SóLOO \\
REACCION & GESTOS \\
\end{tabular} & síno & DESCRIBE & $\begin{array}{l}\text { INTER- } \\
\text { PRETA } \\
\end{array}$ & OPINA & COMPARA & APLICA \\
\hline
\end{tabular}

\footnotetext{
${ }^{6}$ MARTA LAZO, C. (2005), op. cit., págs. 28 y ss.
} 
"realidad" de "realidad mediada", mediante la relación de la realidad con la experiencia directa, se refieren al concepto de "grabación" como manera de construir la realidad e, incluso, hacen alusión a las posibilidades de "manipular" la realidad a través de la televisión.

- En la distinción entre contenidos infantiles y contenidos para adultos. Los niños entre 10 y 12 años que comentan los programas con sus padres y ven menor cantidad de tiempo al día la televisión son quienes más críticos se muestran con la exposición de contenidos para adultos, aunque se presenten en formato de dibujos animados, como sucede con una de las series que nos sirvió de ejemplo en nuestro análisis, "Los Simpson". Por otra parte, los escasos niños que ven "South Park", no tienen pautas de control paterno y presentan un elevado consumo diario. Paradójicamente, reconocen que ven esta serie pese a considerar que está destinada a adultos por el tipo de lenguaje grosero utilizado y por emitirse en horario de madrugada.

\section{ASPECTOS POSITIVOS Y NEGATIVOS DE VER LA TELEVISIÓN CON LOS PADRES: LOS NIÑOS RESPONDEN}

Con el fin de conocer la opinión de los niños en cuanto al consumo compartido, planteamos en los grupos de discusión qué ventajas y qué inconvenientes pensaban que tenía ver la televisión junto con sus padres. De sus respuestas evidenciamos que, en general, se acoge esta práctica como positiva porque estiman que ayuda en los siguientes aspectos:

- para poderles preguntar lo que no entienden y así resolver sus dudas;

- con el fin de contrastar su opinión y ampliar el punto de vista de los temas que se plantean;

- para contar con una orientación de los contenidos que pueden ver y los que no les resultan acordes por su corta edad;

- por el simple hecho de tener compañía durante el visionado. Es significativo que esta última ventaja sólo se plantea por parte de niños que no suelen dialogar con sus padres.

Como excepción, sólo se señala el inconveniente de la diferencia en los gustos televisivos. Esta desventaja se aduce únicamente en grupos que no acostumbran a dialogar con sus padres, en los que se llega a afirmar que estos se "deshacen" de sus hijos para ver únicamente los programas que les gustan.

Cabe indicar que, de forma generalizada, la mayoría de los niños afirman que suelen adecuarse, de forma más frecuente, a las preferencias televisivas de sus padres que estos a los gustos de sus hijos. Esto queda demostrado en que son pocos los padres que ven con los niños los dibujos animados, al contrario de lo que sucede, por ejemplo, con los informativos, contenidos que a pesar de no ser del 
interés de los niños ${ }^{7}$, los ven con ellos por el simple hecho de compartir ese tiempo con sus padres.

Quedan, pues, abiertas algunas cuestiones ¿por qué los padres afirman que no tienen tiempo para ver la televisión son sus hijos, cuando el cómputo de minutos al día de los adultos supera en más de una hora el de los niños? y ¿por qué motivos los padres no se interesan por aquello que están viendo sus hijos, cuando estos ven con ellos programas que no les gustan?, ¿podemos hablar, por tanto, de un consumo compartido sólo cuando los espacios son de la preferencia de los padres?

\section{PAUTAS PARA PADRES PARA UN CONSUMO TELEVISIVO DE CALIDAD JUNTO CON SUS HIJOS}

Ante los beneficios constatados para los niños de compartir el consumo televisivo con adultos y del diálogo respecto a los contenidos vistos, recogemos a continuación una serie de posibles pautas de actuación para los padres en el "contexto perceptivo del hogar":

- Dosificar el tiempo que los niños destinan diariamente a ver televisión.

- Ofrecer otras alternativas en el disfrute del tiempo de ocio.

- Planificar junto con los niños previamente, antes de sentarse frente a la pantalla, los programas que se van a ver.

- Interesarse por los espacios que más atraen a los niños y verlos con ellos.

- Preguntar los motivos por los que les gustan los espacios que eligen, con el fin de encontrar argumentos de cuáles son sus intereses.

- Observar si los niños entienden el contenido de los mensajes y explicarles aquello que no entiendan;.

- Contextualizar aspectos parciales que no queden bien plasmados en las imágenes.

- Potenciar la valoración crítica de los contenidos vistos.

Algunas de estas tareas no poseen un excesivo grado de dificultad para los padres, únicamente exigen un compromiso para con sus hijos, prestando el tiempo necesario y mostrando interés por una cuestión tan importante como es el aprendizaje que la televisión proporciona a los niños.

\footnotetext{
${ }^{7}$ Hay que matizar que, en España, no se han realizado todavía informativos destinados específicamente a niños, como ocurre en otros países, por ejemplo en Francia, Japón, Estados Unidos - Reino Unido. Véanse algunos de estos ejemplos en GARCíA MATILLA, A. (2003): Una televisión para la educación. La utopía posible. Barcelona, Gedisa, págs. 90-92.
} 
La guía en el consumo televisivo...

\section{BIBLIOGRÁFÍA:}

AA.VV. (2002): Libro interactivo Educación para la comunicación, televisión y multimedia. Madrid, Master de Televisión Educativa de la UCM y Corporación Multimedia.

AA.VV. (2001): La nueva era de la televisión. Madrid, Academia de las Ciencias y las Artes de Televisión de España y Corporación Multimedia.

AA.VV. (1994): Televisión. Niños y jóvenes. Valencia, Ente Público RTVV.

AGUADED, J. I. (1999): Convivir con la televisión. Familia, educación y recepción televisiva. Barcelona, Paidós.

ALONSO, M.; MATILLA, L.; y VÁZQUEZ, M. (1995): Teleniños Públicos, Teleniños Privados. Madrid, Ediciones de la Torre.

BOLETÍN DEL CENTRO DE INVESTIGACIONES SOCIOLÓGICAS, CIS, nำ26, Estudio ํำ 2.391: http://www.cis.es/boletin/26/tele.htm.

CANTÚ, A. (1997): "Consumo, recepción y usos. Un juego de implicaciones", en III Jornadas Nacionales de Investigadores en Comunicación: campos de investigación y prácticas. Argentina, Red Nacional de Investigadores en Comunicación, Ponencia publicada en http://geocities.com/CollegePark/5025/mesa2a.htm.

DIAS PACHECO, E. (1998): Televisâo, Criança e Educaçâo. Sao Paulo, Papirus Editora.

FONTCUBERTA, M. (1999): "Educación para la Comunicación en la Sociedad del Conocimiento", en FLORENZANO, R. y MOLINA, J. (coordinadores): Televisión y niños, Corporación de Promoción Universitaria y Televisión Nacional de Chile, Santiago de Chile, págs. 189-199.

FUENZALIDA, V. y HERMOSILLA, Mª E. (1991): El televidente activo (Manual para la recepción activa de televisión). Santiago de Chile, Corporación de Promoción Universitaria.

GARCíA MATILLA, A.; CALLEJO GALLEGO, J. y WALZER, A. (2004): Los niños y los jóvenes frente a las pantallas. Madrid, Ministerio de Trabajo y Asuntos Sociales.

GARCíA MATILLA, A. (2003): Una televisión para la educación. La utopía posible. Barcelona, Gedisa.

LLULL, J. (1990): Inside family viewing. Ethnographic research on television's audiences. Londres-Nueva York, Routledge-Comoedia Book.

MARTA LAZO, C. (2005): La televisión en la mirada de los niños, Madrid, Fragua. (1997): "Análisis empírico sobre la decodificación del mensaje televisivo, según el proceso evolutivo en niños de clase media de 4 a 7 años", en Actas del I Congreso Internacional de Formación y Medios (Ponencias y Comunicaciones). Segovia, Universidad de Valladolid, págs. 327-333.

MORLEY, D. (1986): Family television: Cultural power and domestic leisure. Londres, Sage. 
De los resultados de este análisis, se desprenden los beneficios de conversar con los padres y de mantener un consumo televisivo por debajo de las dos horas diarias, en los siguientes aspectos:

- En el mayor grado de actividad en la interacción con el medio. Si bien constatamos que, en general, los niños actúan de forma activa ante los mensajes televisivos, siendo su nivel de actividad "alto", determinamos que existen diferencias sustanciales en cuanto a las variables de estudio. De tal modo que quienes acostumbran a contrastar los contenidos televisivos con sus padres suelen alcanzar niveles de actividad superiores a los propios de su edad. Por ello, los niños entre 7 y 9 años que comentan la programación con sus padres alcanzan percepciones similares a las de los escolares entre 10 y 12 años. En sus lecturas de los mensajes se aprecian más interpretaciones y opiniones, mientras que quienes no conversan con ellos se limitan a describirlos de manera lineal o fragmentada. Además, los niños que ven menos de dos horas diarias la televisión y dialogan con sus padres son quienes alcanzan mayores niveles de actividad, llegando al estadio considerado "muy alto", en el que establecen relaciones con lo que ya conocen (comparaciones) u ofrecen otras alternativas y crean nuevos escenarios (aplicaciones). En contraposición, los que superan las dos horas introducen errores en la interpretación de las secuencias.

- En la comprensión de los valores y "contravalores" que se introducen en las imágenes. Quienes dialogan con los padres y presentan un consumo menor perciben en mayor medida los valores y contravalores insertos en los mensajes televisivos. El hecho de contar con referencias previas de los temas expuestos en las imágenes, como por ejemplo el reciclaje, favorece la advertencia, extrapolación y explicación argumentada de los valores positivos y negativos que se asientan en los mensajes.

- En la percepción de los aspectos críticos que se introducen en los mensajes. Los niños cuyo consumo es elevado presentan confusiones en la reinterpretación de secuencias con contenido crítico, además no captan el sentido nuclear de los mensajes. Por el contrario, quienes limitan su consumo son quienes llegan a profundizar más en el contenido de las imágenes.

- En la diferenciación entre realidad y ficción. La edad es una variable clave en la distinción entre ambos conceptos, ya que los niños entre 7 y 9 años suelen relacionar la realidad con todo aquello que pueda acontecer en la vida real, por ello asocian las series de ficción con lo real y los contenidos informativos con lo ficticio, cuando les resultan hechos extraños o extraordinarios. Por otro lado, en el grupo entre 10 y 12 años, los niños que no acostumbran a dialogar con sus padres y su consumo es superior a las dos horas diarias también suelen cometer equívocos en la interpretación de ambos términos. De manera contraria, los niños que sí conversan de manera habitual con los mayores y ven menos de dos horas diarias la televisión evidencian el significado de ambos conceptos y, además, llegan a diferenciar 
PÉREZ ORNIA, J.R. y NÚÑEZ LADEVÉZE, L. (2003): "Programación infantil en la televisión española: Inadecuada relación entre oferta y demanda", en TELOS, Cuadernos de Comunicación, Tecnología y Sociedad, no 54 segunda época. Fundación Telefónica, págs. 103-113.

VAN EVRA, J. (1990): Television and child development. New Jersey, Erlbaum.

(Recibido el 27-03-06, aceptado el 2-05-06) 